\title{
Abandonment: Experiences of accessing emergency services during mental health crisis
}

\section{A.R. Lovelace, L. Phelan, R. Langer, M. Fergusson, L. Gagnon}

Amy Rene Lovelace, RMT, BScN

Undergraduate Student, School of Nursing

Laurentian University

alovelace@laurentian.ca

Liam Phelan, BScN

Undergraduate Student, School of Nursing

Laurentian University

lphelan@laurentian.ca

Rosanna Langer, BA, LLB, LLM, PhD

Associate Professor, Department of Law and Justice

Laurentian University

rlanger@laurentian.ca

Moira Fergusson, CCW, BA, MA, PhD

Seessional Faculty, Sociology and Labour Studies

Laurentian University

mx_ferguson@laurentian.ca

Lissa L. Gagnon, RN, BScN, MScN

Assistant Professor, School of Nursing

Laurentian University

lgagnon@laurentian.ca 


\begin{abstract}
Purpose: Emergency departments (ED's) often serve as the access point to health services for individuals living with mental health challenges, with mental health crisis (MHC) accounting for $15 \%$ of all presentations to ED's in Canada. Consumers' experiences of emergency mental health services have widely been reported as negative. This research aims to explore the experiences of individuals accessing the ED for MHC.

Method: A supra-analysis was conducted using data from four semi-structured interviews collected from a larger study exploring stigma, discrimination and resilience in people experiencing mental health challenges. Supra-analysis aims to explore an aspect of the data from a different theoretical perspective. Transcripts were selected based on a participant history of voluntarily accessing emergency services for MHC. Data analysis was completed using the process of thematic analysis which involved immersion in the data, the development and refinement of codes leading to themes.

Findings: A major theme of abandonment was identified in participant interviews with subthemes of; geographic, socioemotional and therapeutic abandonment. Participants reported that the locations of care, lack of social/emotional engagement and lack of health care providers' (HCP) knowledge led to negative experiences attending ED's. Participants also reported a lack of desire to access emergency services in the future.

Conclusion: Future research is vital to enhance the delivery of emergency services, to reduce the feelings of abandonment experienced by individuals accessing the ED for MHC. Training and education must be provided to HCP's staffing ED's that focuses on providing high quality, appropriate emergency services to this vulnerable population.
\end{abstract}

Key words: Mental illness, Mental health crisis, Emergency care, Experiential, Healthcare, Patient perspective 


\section{Résumé}

Objectif : Les services des urgences servent souvent de point d'accès aux services de santé pour les personnes aux prises avec des problèmes de santé mentale. La crise de santé mentale (CSM) représente $15 \%$ de toutes les présentations aux urgences au Canada. Les expériences des consommateurs en matière de services de santé mentale d'urgence ont été largement rapportées comme négatives. Cette présentation vise à explorer les expériences des individus accédant à l'ED pour CSM.

Méthode : Une supra-analyse a été menée en utilisant les données de quatre entrevues semistructurées recueillies dans une étude plus vaste sur la stigmatisation, la discrimination et la résilience chez les personnes aux prises avec des problèmes de santé mentale. La supra-analyse vise à explorer un aspect des données à partir d'une perspective théorique différente. Les relevés de notes ont été sélectionnés en fonction de l'historique d'accès volontaire des participants aux services d'urgence pour CSM. L'analyse des données a été complétée en utilisant le processus d'analyse thématique qui impliquait l'immersion dans les données, le développement et l'affinement des codes menant à des thèmes.

Constatations : Un thème majeur de l'abandon a été identifié dans les entrevues des participants avec des sous-thèmes de; abandon géographique, socio-émotionnel et thérapeutique. Les participants ont signalé que les lieux de soins, le manque d'engagement social et émotionnel et le manque de connaissances des fournisseurs de soins de santé ont mené à des expériences négatives dans les urgences. Les participants ont également signalé un manque de désir d'accéder aux services d'urgence à l'avenir.

Conclusion : Les recherches futures sont essentielles pour améliorer la prestation des services d'urgence, afin de réduire le sentiment d'abandon ressenti par les personnes qui accèdent à l'urgence pour le $\mathrm{CMH}$. La formation et l'éducation doivent être fournies aux services d'urgence du personnel de santé qui se concentre sur la fourniture de services d'urgence appropriés et de haute qualité à cette population vulnérable. 


\section{Introduction}

The mental health of Canadians is a significant issue, with half of the population likely to experience mental illness by age 40 (Mental Health Commission of Canada, 2013). Winters, Megalhaes and Kinsella (2015) describe the manifestation of mental health crisis through various signs such as agitation, anxiety, or anger which result from feeling overwhelmed or a lack of control. Crisis becomes an emergency when it places an individual in imminent risk to them self or others. Emergency departments (EDs) often serve as the access point for individuals living with mental health challenges, with mental health crisis accounting for as much as $15 \%$ of all ED presentations (Clarke, Usick, Sanderson, Giles-Smith, \& Baker, 2014).

Patient experiences as consumers of mental health services at EDs has been largely negative (Clarke et al., 2014; Harris et al., 2016). Lack of health care provider awareness of the needs of mental health consumers in the ED results in stigma felt by individuals which results in increased ED visits and admissions and reduces quality of care (Clarke et al., 2014; Gerdtz, Weiland, Jelinkek, MacKinlay, \& Hill, 2012; Plant \& White, 2013). Environmental factors such as noisy, stimulating, fast paced environments lacking in privacy are cited as factors contributing to poor patient experiences (Clarke et al. 2014; Gerdtz, Weiland, Jelinkek, MacKinlay, \& Hill, 2012). Heavy workloads leading to decreased time for client interactions and inadequate training and skills for assessing psychiatric conditions can result in inadequate triage leading to increased wait times (Plant \& White, 2013). The appropriateness of EDs for mental health crisis are heavily influenced by consumers' perceived quality of care (Carstensen et al., 2017). There is currently little published Canadian evidence discussing mental health care consumers' experiences in ED from the clients' perspective.

The aim of this research is to explore the experiences and understand their associated meaning for individuals voluntarily accessing the ED for mental health crisis in a Northern Ontario City. The research question for this current study is: What are the experiences of individuals voluntarily accessing the ED for mental health services in Northern Ontario?

\section{Methodology}

Braun and Clark's (2006) thematic analysis was utilized to capture participants' lived experience regarding accessing the ED for mental health crisis. Identifying the theoretical framework underlying data analysis is essential, as it provides the foundation for constructing knowledge. Contextualism blends realist and constructivist paradigms, allowing the meaning of experiences to be explored within the larger social context. Exploring consumers' perceptions of psychiatric interventions is essential to determining their efficacy (Carstensen et al., 2017). It is essential to explore the experiences of consumers of mental health services in the ED within the unique social context of Northern Ontario, as individuals ascribe meaning to their experience dependent of their context.

A supra-analysis was conducted using data from a larger study exploring stigma, discrimination and resilience in persons experiencing mental health challenges. Supra-analysis is 
an applicable form of secondary analysis as it allows researchers to investigate new research questions from previously collected data. It allows an aspect of the collected data to be viewed from a different theoretical perspective than the larger study (Heaton, 2008).

Ethical approval to conduct the study was granted to the authors from the research ethics board of their academic institution. Participants received a consent form and demographic checklist to read and voluntarily complete. The researchers have taken measures to ensure the anonymity of participants by removing any identifying information and assigning codes for the purposes of data management

Four transcripts were selected from the five voice recorded semi-structured interviews that had been transcribed and were ready for analysis. Purposive sampling was used to select all transcripts in which the participant had accessed emergency services for mental health crisis. These were preliminary findings of the larger study which contained 20 interviews. One question, Please describe your experiences accessing the ED for mental health crisis, as well as associated prompts, were selected to gain insight into individuals' experiences accessing mental health services in the ED. A literature review was conducted in CINAHL, OVID, ProQuest and PubMed for research articles or dissertations on the topic of adult mental health consumers' experiences with emergency services. The following keywords were included in the search; mental disorder; mental health; mental illness; emergency services; emergency services, psychiatric; ED; Canada. Inclusion criteria were English language, peer reviewed articles or dissertations published between 2007 and 2017 that included adult Canadian consumer perspectives of emergency services provided during mental health crisis. Twenty articles were reviewed, with five articles accepted for relevance to the research question. The literature search was conducted early in the analysis phase in order to become more familiar with subtleties present in the data (Braun \& Clarke, 2006).

A six stage process of thematic analysis was selected as the form of data analysis (Braun \& Clarke, 2006). The process defined by Braun and Clark involves immersion in the data, generating initial codes, searching for themes, reviewing themes, defining and naming themes, and producing the report. Ten pages of data from the four relevant interviews were analyzed. The researchers immersed themselves in the data through actively listening, reading and making notes on commonalities and differences within the narratives during the interviews, transcription and post transcription processes. The transcripts were assigned letters A through D to ensure the anonymity of the participants. The data set was reviewed completely and elements of the data were given unique descriptors, first level codes which were assigned by paragraph. After the initial coding of the data was completed similar elements of the narrative were organized into themes. The relationships between the codes within individual themes as well as the relationship between the themes was explored. The researchers then came together and formed consensus on the fit of individual codes within the larger themes and the ability of the themes to capture, as a whole, participants' experiences that were present in the data set. Finally the researchers explored the essence of the themes and applied labels that captured the participants experiences present in the data. This process allowed the researchers to define the main theme of abandonment and three related subthemes of geographical, socioemotional, and therapeutic abandonment. 


\section{Findings}

Participants were active members of a community resource center for people living with mental health challenges. Participants drew from past and present experiences in the ED. The sample was comprised of four individuals' experiences, two males and two females. Their ages ranged from 18 to 65 .

For individuals voluntarily accessing emergency mental health services abandonment was experienced by participants as geographical abandonment, socioemotional abandonment and therapeutic abandonment.

\section{Geographical Abandonment}

Absence of support was experienced as prolonged wait times, lack of health care provider physical presence, and long periods of isolation.

"They left me in the room all night...and then no one really checked on me the rest of the night"

"I've been in there sitting there for hours and feeling like incredibly anxious with all the other people around and everything that was going on, so yeah, no I wasn't given a room."

Structural and physical elements of ED led to the breakdown of the participants' experience. Extended wait times in waiting rooms, for triage, to be taken to an exam room, and to be treated by a health care professional were reported, which was contrasted by the limited amount of time they spent engaged with health care providers during assessment and discharge. Participants experienced extended isolation, both when alone in rooms, and in large waiting areas that they described as a lack of physical presence of health care providers.

\section{Socioemotional Abandonment}

Participants experienced a lack of engagement as being moved through the system, a lack of acknowledgement of their situation and feeling unheard.

"He wasn't very engaging, he looked down at his clipboard the whole time, he asked me if I was suicidal"

"No one was really listening. I didn't feel like I was being heard, in terms of what I was saying, I can't manage anymore"

Participants describe feeling as though they were being ushered through the steps necessary to be triaged, assessed and treated without acknowledgement of their psychosocial needs. A lack of empathetic engagement on an interpersonal level was described in participant experiences. Participants describe their crisis as complex phenomena that were overwhelming, emotionally 
challenging, and that they were no longer able to manage without assistance. The limited interaction and lack of acknowledgement of the participants struggle by health care providers led the participants to feel unheard, and not understood. These factors led to the breakdown of the provider-client relationship as participants sought a human connection that was unmet.

\section{Therapeutic Abandonment}

Participants described having unmet needs related to a non-holistic approach being taken by health care providers, lack of shared decision making and a lack of crisis resolution.

"When I tried telling him about the concerns I had about past side effects from antidepressants he blew me off."

"And then they sent me on my way. I was a little shocked because nothing was resolved."

Participants describe their experience as being "very medical". They felt that the health care provided focused on the physiological aspects of their presentation while not addressing the unique personal knowledge of their care needs developed through their lived experience. Participants describe unilateral decisions regarding care and medication regimes that did not consider participant desires or beliefs leading to dissatisfaction with the care provided. Ultimately many participants left the ED feeling as though their crisis was unresolved, and that their time had been squandered.

\section{Discussion}

Abandonment can be experienced in relation to physical space and distance of health care providers, through lack of therapeutic engagement and through inappropriate focus of care (Clarke, Dusome, \& Hughes, 2007; Da Silva Elias, De Melo Tavares, \& Cortez, 2013). In this study, participants accessing ED for mental health crisis were unsatisfied with the care they received and often felt that the level of care provided did not address their psychosocial needs. Participants were often left for hours with no follow up care in environments that were either too stimulating or isolated. Being present with a client includes listening, understanding, communicating with and checking on clients while they are receiving care (Mohammadipour, Atashzadeh-Shoorideh, Parvizy, \& Hosseini, 2017). A lack of engagement with participants created an environment where they did not feel valued as human beings as they felt their psychosocial needs were unheard and not adequately addressed. Absence and lack of engagement creates relational emptiness because a common purpose or meaning has not been established in the client- health care provider relationship (Thibeault, 2010). Clients have unmet needs when there is a difference between their perception of the crisis and the health care provider focus. Participants described health care providers attending to physical concerns rather than psychosocial considerations. Failure of the health care provider to meet these needs results in a form of socioemotional abandonment. These factors contribute to the experiences of abandonment in clients which leads to a negative 
association with ED. Participants indicated that they were less likely to access ED in the future as a result of their experiences

\section{Implications}

These preliminary findings reveal that the elements necessary to establish therapeutic relationships with health care providers were not present in participants' experiences. The authors recognize the unique challenges to developing therapeutic relationships within the ED setting that will meet the psychosocial needs of individuals experiencing mental health crisis. However, given that it is often the first point of contact it is essential for ED health care providers to develop these relational skills through education and in service training. Educational programs that teach communication strategies and the importance of an empathetic approach to the psychosocial aspects of mental health are needed to address the service gap experienced by individuals presenting with mental health crisis.

\section{Research Limitations and Further Directions for Study}

The findings of this qualitative study are not meant to be transferable to other participant experiences'. It is recognized that the findings reflect the experiences of a sample of participants and not those of all individuals.

The literature is currently sparse in exploring this topic in the Canadian context, particularly from the perspectives of mental health consumers. Additional empirical research is needed to capture the essence of ED experiences in mental health crisis from the clients' perspective. Such information could add to the knowledge regarding client experiences in the ED, and support interdisciplinary health care providers to further assist clients experiencing mental health crisis.

\section{Acknowledgement}

The authors would like to thank the participants who willingly shared their experiences and perspectives of mental health. 


\section{References}

Braun, V., \& Clarke, V. (2006). Using thematic analysis in psychology. Qualitative Research in Psychology, 3, 77-101. Retrieved from http://www.informaworld.com/smpp/content $\sim \mathrm{db}=$ all $\sim$ content=a795127197 frm=titlelink.

Carstensen, K., Lou, S., Groth Jensen, L., Konstantin Nissen, N., Ortenblad, L., Pfau, M., \& Vedel Ankersen, P. (2017). Psychiatric service users' experiences of emergency departments: a CERQual review of qualitative studies. Nordic Journal of Psychiatry, 7, 315-323. doi: 10.1080/08039488.2017.1288759

Clarke, D., Dusome, D., \& Hughes, L. (2007). ED from the mental health client's perspective. International Journal of Mental Helath Nursing, 16, 126-131. doi: 10.1111/j.14470349.2007.00455.x

Clarke, D., Usick, R., Sanderson, A., Giles- Smith, L., \& Baker, J. (2014). Emergency department staff attitudes towards mental health consumers: A literature review and thematic content analysis. International Journal of Mental Health Nursing, 23, 273-284. doi:10.1111/inm.12040

Da Silva Elias, A., De Melo Tavares, C. M., \& Cortez, E.A. (2013). Impact of stigma of madness on the attention of nursing to psychiatric patient in emergency situation. Ciencia, Cuidado e Saude, 12(4), 776-783. doi: 10.4025/cienccuidsaude.v12i4.22553

Gerdtz, M., Weiland, T., Jelinet, G., Mackinlay, C., \& Hill, N. (2012). Perspectives of ED staff on the triage of mental health-related presentations: implications for education, policy and practice. Emergency Medicine Australasia, 24, 492-500. doi: 10.1111/j.17426723.2012.01592.x

Harris, B., Beurmann, R., Fagien, S., \& Shattell, M. (2016). Patients' experiences of psychiatric care in EDs: A secondary analysis. International Emergency Nursing Journal, 26, 14-19. doi: 10.1016/j.ienj.2015.09.004

Heaton, J. (2008). Secondary analysis of qualitative data: An overview. Historical Social Research, 33(3), 33-45.Retrieved from: http://www.jstor.org/stable/20762299

Mental Health Commission of Canada. (2013). Making the case for investing in mental health in Canada. Unknown: Author. Retrieved from https://www.mentalhealthcommission.ca/sites/default/files/201606/Investing_in_Mental_Health_FINAL_Version_ENG.pdf

Mind. (2015). Listening to experience: an independent inquiry into acute and crisis mental healthcare London, UK: Author. Retrieved from: https://www.mind.org.uk/media/211306/listening_to_experience_web.pdf

Mohammadipour, F., Atashzadeh- Shoorideh, F., Parvizy, S., \& Hosseini, M. (2017). An explanatory study on the concept of nursing presence from the perspective of patients 
admitted to hospitals. Journal of Clinical Nursing, 26, 4313-4324. doi:

10.1111/jocn.13578

Nicholls, D., Gaynor, N., Shafiei, T., Bosanac, P., \& Farrell, G. (2011). Mental health nursing in EDs: the case for a nurse practitioner role. Journal of Clinical Nursing, 20, 530-536. doi: 10.1111/j.1365-2702.2010.03504.x

Plant, L., \& White, J. (2013). Emergency room psychiatric services: A qualitative study of nurses' experiences. Issues in Mental Health Nursing, 34, 240-248. doi: $10.3109 / 01612840.2012 .718045$

Thibeault, C. (2010). The relationships of hospitalized persons with acute mental illness and their nurses: An interpretive inquiry. (Doctoral dissertation). Retrieved from:http://digitool.library.mcgill.ca/webclient/StreamGate?folder_id=0\&dvs=15154338 82944 335\&usePid1=true\&usePid2=true

Winters, S., Magalhaes, L., \& Kinsella, E.A. (2015). Interprofessional collaboration in mental health crisis response systems: a scoping review. Disability and Rehabilitation, 37(23), 2212-2224. doi.10.3109/09638288.2014.1002576 